\title{
MANUFACTURE AND PERFORMANCE EVALUATION OF A COMBINATION MACHINE FOR CHOPPING AND MILLING ARUNDO DONAX (PART II)
}

\author{
El-Sharabasy, M. M. A. ${ }^{1}$
}

M. M. Badr ${ }^{2}$

\section{ABSTRACT}

The aim of the present work was to manufacture and evaluate the performance of a combination machine to be suitable for chopping and milling the Arundo donax stalks so as to use the final product in many industrial applications such as: making compost to improve soil properties, energy source (direct burning and biogas generation) and compressed wood. The performance of the combination machine was studied under the following parameters: drum speed, moisture content and feed rate. The performance of the manufactured machine was evaluated taking into consideration the following indicators: cut length distribution, machine productivity, fineness degrees, specific energy and operational cost. The experimental results reveal that the highest values of cut length percentage < 2 up to $4 \mathrm{~cm}$, machine productivity and fine degree were $(78.95 \%, 600 \mathrm{~kg} / \mathrm{h}$ and $82.87 \%$ ) respectively, while the lowest values of the specific energy and operational cost were $(71.08 \mathrm{~kW} . \mathrm{h} / \mathrm{Mg}$ and $33.33 \mathrm{L.E} / \mathrm{Mg})$, respectively under the following conditions: drum speed of about $1300 \mathrm{rpm}$, stalks moisture content of $14 \%$ with adjusting feed rate at $700 \mathrm{~kg} / \mathrm{h}$.

\section{INTRODUCTION}

rundo donax (Giant reed) is a tall, erect, perennial cane-or reed-like
grass, 2 to 8 meters high. It is one of the largest of the herbaceous
grasses. The fleshy, almost bulbous, creeping root stocks form compact masses from which arise tough, fibrous roots that penetrate deeply into the soil. The culms reach a diameter of 1 to $4 \mathrm{~cm}$ and commonly branch during the second year of growth. These culms are hollow, with walls 2 to 7 $\mathrm{mm}$ thick and divided by partitions at the nodes. The nodes vary in length from 12 to $30 \mathrm{~cm}$. The canes are used for many different purposes such as roof thatching, fishing rods, reeds in woodwind instruments, etc.

\footnotetext{
${ }^{1}$ Assist. Prof. of Agric. Eng., Fac. of Agric., Zagazig Univ., Egypt.

${ }^{2}$ Lecturer of Agric. Eng., Fac. of Agric., Zagazig Univ., Egypt.
} 
It is one of the largest herbaceous grasses and even though Arundo donax is a $\mathrm{C}_{3}$ plant, it shows high photosynthetic rates and unsaturated photosynthetic potential in comparison with $\mathrm{C}_{4}$ plants, (Pilu et al. 2012). Heaton et al. (2004) reported that giant reed is one of the most promising crop for energy production for the Mediterranean climate of Europe and Africa, where it has showed advantages as indigenous crop (already adapted to the environment), durable yields, and resistance to long drought period. Several field studies have highlighted the beneficial effect of giant reed crop on the environment due to its minimal soil tillage, fertilizer and pesticide. Furthermore it offers protection against soil erosion. One of the most important land degradation processes in Mediterranean and US environments. Arundo donax bio-energy feedstock has an impressive potential for several conversion processes. Dried biomass has a direct combustion high heating value of $8000 \mathrm{BTUs} / \mathrm{lb}$. Spencer (2006) found that Arundo donax has very high amounts of biomass per unit of land area as documented in many studies looking at standing biomass of wild infestations and annual productivity of cultivated stands. This study found an adjusted Arundo stand biomass of $15.5 \mathrm{~kg} / \mathrm{m}^{2}$, which is corroborated by the most comprehensive study evaluating Arundo biomass. The large amount of biomass is related to high productivity of the plant, high density of individuals (high cane density), and tall growth form of the plant (average $6.5 \mathrm{~m}$ ). In addition to the high amount of biomass per unit of land area, Arundo has a large amount of energy per unit of dry weight (17 MJ/kg to $19.8 \mathrm{MJ} / \mathrm{kg}$ ). These values compare favorably with other fuel crops (Arundo is one of the highest) and are higher than most native tree, scrub, and herbaceous assemblages in the riparian zone. This is why fuel crop producers consider Arundo one of the top potential biofuel crops. Guthrie (2007) mentioned that Arundo donax plants are often used as erosion control because the root masses stabilize stream banks and terraces. Arundo has been suggested as a source of biomass for fuel energy production. It does not make a good livestock forage because the leaves mature and become unpalatable quickly. Leaves may be woven into mats and baskets. Stems can be used for building material, plant supports, fences, screens, roofing, walking sticks, measuring rods, fishing poles and brooms. The stems are used make musical instruments like clarinets and bag-pipes. Young stems or branches can be used in roof thatching. The stem fiber can be used to make 
paper. Rhizomes are edible, raw or cooked. They can be dried out and ground into a powder to make bread, usually in conjunction with cereal flours. Arundo is also used to treat dropsy. Elfatih et al. (2010) modified and evaluated a machine for rice straw chopping under the supervision of Agricultural Engineering Research Institute and National Research Center. They found that increasing the cutting drum linear speed from $56.6 \mathrm{~m} / \mathrm{s}$ to $70.7 \mathrm{~m} / \mathrm{s}$, increased the cutting efficiency, the chopper productivity, and the power requirement by percentage of $3.7 \%, 2.8 \%$ and $0.9 \%, 57.5 \%, 55.9 \%$ and $41.7 \%, 36.8 \%, 28.6 \%$ and $35.9 \%$, respectively, meanwhile, decreased the energy consumption by percentage of $32.7 \%$, 38.4 and $9 \%$ for $35 \mathrm{~mm}, 25$ $\mathrm{mm}$, and $9 \mathrm{~mm}$ concave hole diameter, respectively. The shortest composting period 95 days has been resulted using $25 \mathrm{~mm}$ concave holes diameter at 66 $\mathrm{m} / \mathrm{s}$ cutting drum speed, meanwhile the longest period 140 days has been resulted using the $9 \mathrm{~mm}$ concave holes diameter at $70.7 \mathrm{~m} / \mathrm{s}$ cutting drum speed. Also, it has been resulted using the $35 \mathrm{~mm}$ concave holes diameter at $56.6 \mathrm{~m} / \mathrm{s}$ cutting drum speed. The highest cost was 240.7 L.E/Mg, Meanwhile the lowest cost was 129.2 L.E/Mg. Solomon Tekeste (2012) developed an engine-driven chopper for chopping the crop residue and hay. The machine was designed with the following main components: feed chopper, rotating drum with swinging knives, casing with fixed knives welded on it, a screen and stands. The machine was tested to evaluate its performance. The test was conducted using three levels of drum speeds: 960, 1200 and $1400 \mathrm{rpm}$, and three feed rates: 420,540 and $660 \mathrm{~kg} \mathrm{~h}^{-1}$. The test result showed that the optimum drum speed and feed rate values for both maize stalk and grass were $1200 \mathrm{rpm} 540 \mathrm{~kg} \mathrm{~h}^{-1}$, respectively. The average size reduction percentage using these optimum combinations was $92.0 \%$ and $79.5 \%$ for maize stalk and grass respectively. The machine performed well with output rate ranging from 420 to $660 \mathrm{~kg} / \mathrm{h}$ and specific energy requirement of 11 to $20 \mathrm{KJ} \mathrm{kg}^{-1}$ output.

So, such care had to be taken to manufacture and operate the combination machine for chopping and milling Arundo donax to be suitable for different technique industries. Thus, the objectives of this research are to:

- Manufacture a combination machine to be suitable for chopping and milling the Arundo donax. 
- Optimize some operating parameters: drum speed, moisture content and feed rate affecting the performance of the combination machine.

- Evaluate the manufactured machine from the economic standpoint.

\section{MATERIALS AND METHOD}

The experiments were conducted through the year of 2014 at Department of Agricultural Engineering, Faculty of Agriculture, Zagazig University to design and manufacture a combination machine to be suitable for chopping and milling the Arundo donax plant so as to use the product in many industrial applications such as: animal feeding, making compost to improve soil properties, energy source (direct burning and biogas generation) and compressed wood.

\subsection{MATERIALS:}

\subsubsection{The used plant:}

Arundo donax (giant reed) was used in this study at different moisture contents. Some Physical characteristics of the used Arundo donax were determined before chopping and milling operations such as: length of plant, diameter of stalk, stalk thickness, and mass of 10 stalks. As well as, chemical analysis has been estimated for Arundo donax plants.

\subsubsection{The manufactured combination machine:}

The combination machine suitable for chopping and milling Arundo donax was manufactured from low cost and local materials at a private workshop in Zagazig city, Sharkia Governorate. It consists of the main following parts as shown in Fig.1.

\section{A- Chopping unit:}

The chopping unit consists of the following parts:

1) Feed inlet: The chopping unit was supported with a horizontal feed inlet begins with a wide opening of $66 \mathrm{~cm}$ in width and $12 \mathrm{~cm}$ in height and ends with a small opening of $36 \mathrm{~cm}$ in width and $8 \mathrm{~cm}$ in height to guide the Arundo donax stalks towards the feeding drums locating at the end of the feed inlet. The feed inlet has also three inclination sides with total height of $30 \mathrm{~cm}$. (Fig.1).

2) Feeding drums: The chopping unit was supported with two drums having dimensions of $8 \mathrm{~cm}$ in diameter and $36 \mathrm{~cm}$ in length for each one located at the end of the feed inlet to hold and guide the Arundo donax stalks with adequate feed rate to the chopping unit. 


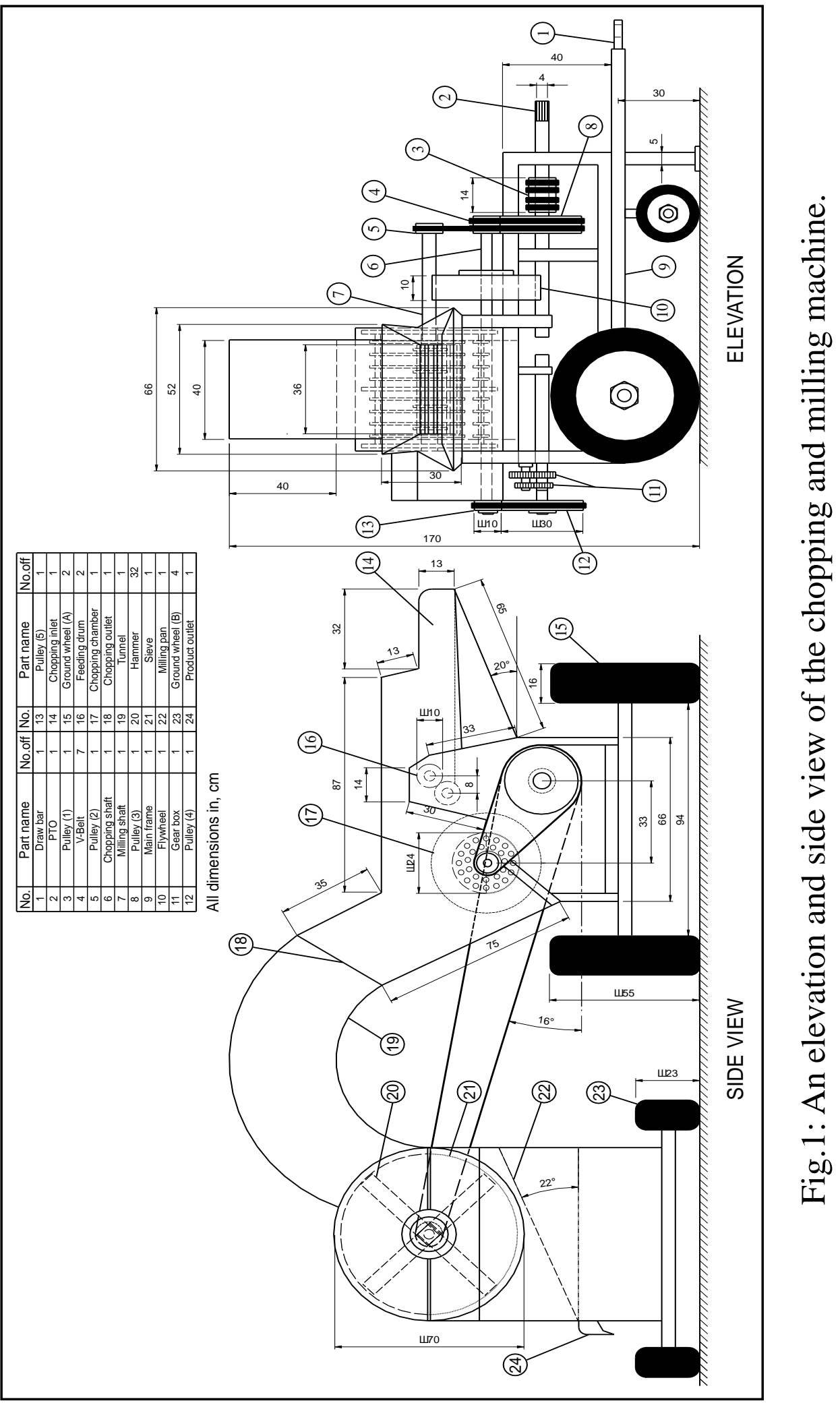

Misr J. Ag. Eng., April 2014 
3) Chopping drum: The chopping drum is a horizontal steel shaft with $5 \mathrm{~cm}$ in diameter and $50 \mathrm{~cm}$ in length laid on two horizontal bearings and supported with two steel shears each one ends with a sharp blade having dimensions of $50 \mathrm{~cm}$ in length, $9 \mathrm{~cm}$ in width and $3 \mathrm{~mm}$ in thickness. The sharp blade was fixed on the steel shear using four Hex. Hd bolts and nuts at inclination angle of $28^{\circ}$ to introduce Arundo donax stalks to the blades consequently with less shearing forces. The inclination chopping blades play as a centrifugal fan to move the chopped materials towards the outlet.

4) Outlet: The outlet having dimensions of $40 \mathrm{~cm}$ in width, $35 \mathrm{~cm}$ in height and $130 \mathrm{~cm}$ in length with curved shape to facilitate moving chopped materials into the milling unit.

\section{B- Milling unit:}

The milling unit consists of the following parts:

1) Feed hopper: The outlet of the chopping unit with the dimensions mentioned above plays as the inlet of the milling unit which guides the chopped materials through this tunnel towards the milling chamber with adequate feed rate. (Fig.1).

2) Milling chamber: The milling chamber consists of three main parts as follows:

- Milling drum: The milling drum is a horizontal steel shaft with $6 \mathrm{~cm}$ in diameter and $50 \mathrm{~cm}$ in length laid on two horizontal bearings and supported with three steel flanges having diameter of $50 \mathrm{~cm}$ and thickness $15 \mathrm{~mm}$, each flange was bored at its outer circumference to receive four steel shafts with total length of $48 \mathrm{~cm}$ and $2 \mathrm{~cm}$ diameter. Each shaft loaded with 8 equal hammers, each one having dimensions of $(35 \times 6 \times 1 \mathrm{~cm})$. The milling drum has totally 32 hammers with $5 \mathrm{~cm}$ between each one on the same shaft.

- Cover: The upper half of the milling chamber was supported with inner steel serrated part in the middle of the cover with total length of $65 \mathrm{~cm}$ on the circumference and average thickness of $3 \mathrm{~cm}$ to serve as a cover of the concave and helps the hammers to more act on the chopped materials.

- Concave: The lower half of the milling chamber is a sieve with total length of $70 \mathrm{~cm}$ and width of $50 \mathrm{~cm}$ bored with $6 \mathrm{~mm}$ holes diameter. The milled materials pass down on the slide pan under milling chamber with inclination angle of $22^{\circ}$ on horizontal to facilitate milling materials moving towards the outlet. 


\section{C- Power transmission:}

The combination machine was powered by a small tractor type (KubotaM5400) with engine power of $42.65 \mathrm{~kW}$ (58hp) at rated speed of $3000 \mathrm{rpm}$. In average it will be about $37 \mathrm{~kW}$ at tractor (pto). This tractor power was chosen to cover the power required to operate the machine $(31.5 \mathrm{~kW})$ which was calculated theoretically. The tractor engine transmits its rotating motion to the combination machine by means of double groove pulley with $10 \mathrm{~cm}$ in diameter and two V-belts powered from tractor (pto) to obtain the rotating speed for both chopping and milling units. Also a flywheel was attached to the chopping shaft to stop the reduction of the rotating speed noticed whenever much stalk materials were added to the chopping chamber.

\section{D- The main frame:}

The main frame of the combination machine for chopping and milling Arundo donax stalks is made from iron steel sheet. It includes three hitching points to be drawn with a small tractor and take its rotating motion from (pto) using pulleys and V-Belts. The combination machine was carried by four ground wheels with $55 \mathrm{~cm}$ in diameter; two wheels for chopping unit and the other two wheels for the milling unit. (Fig.1).

\subsection{METHOD:}

\subsubsection{Preliminary experiments:}

Preliminary experiments were carried out to evaluate the performance of the manufactured machine to be suitable for chopping and milling Arundo donax to be suitable for different technique industries. Modifications were conducted in chopping and milling units to obtain the desirable cutting length and milling products.

\subsubsection{Experimental conditions:}

The performance of the manufactured machine was experimentally measured under the following parameters for chopping operation:

- Four different feed rates of $(500,600,700$, and $800 \mathrm{~kg} / \mathrm{h})$.

- Four different chopping drum speeds of (1000, 1200, 1300, and $1400 \mathrm{rpm})$ or $(18.32,21.98,23.81$ and $25.64 \mathrm{~m} / \mathrm{s})$.

- Four different ears moisture contents of $(12,14,16$, and $18 \%)$.

- The milling operation was carried out under the following constant parameters: hammer milling speed of $1700 \mathrm{rpm}(35.59 \mathrm{~m} / \mathrm{s})$ and screen openings of $6 \mathrm{~mm}$. 


\subsubsection{Measurements and determinations:}

Evaluation of the performance of the combination machine for chopping and milling Arundo donax was based on the following indicators:

- Machine productivity: The machine productivity for chopping and milling operations was determined using the following equation:

$$
\mathrm{Mp}=\frac{\mathrm{Ms}}{\mathrm{t}}, \mathrm{kg} / \mathrm{h}
$$

Where:

$\mathrm{Mp}=$ machine productivity, $\mathrm{kg} / \mathrm{h}$.

Ms = mass of milled Arundo donax sample, $\mathrm{kg}$.

$\mathrm{t}=$ time consumed in the chopping and milling operations, $\mathrm{h}$.

- Cut length percentage measuring: Randomized samples of chopped Arundo donax were taken after each treatment to determine the actual length for each group.

- Fineness degree (particle size distribution): The ground Arundo donax samples were classified into three main categories according to Henderson and Hansen (1968). The first one is fine milled FMC $(<3 \mathrm{~mm})$, the second is medium milled MMC (3-4.2 mm) and the third is coarse milled CMC (> $4.2 \mathrm{~mm}$ ).

- Required power: The following formula was used to estimate the required power. (Hunt, 1983):

$\mathrm{Po}=\left[\right.$ F.C $(1 / 3600) \rho f \times$ L.C.V $\left.\times 427 \times \eta_{\mathrm{thb}} \times \eta_{\mathrm{m}} \times(1 / 75) \times(1 / 1.36)\right], \mathrm{kW}$

Where:

F.C = Fuel consumption, $(1 / \mathrm{h})$.

of $=$ Density of fuel, $(\mathrm{kg} / \mathrm{l})$, (for gasoline $=0.85)$.

L.C.V = Calorific value of fuel, $(10.000 \mathrm{k} . \mathrm{cal} / \mathrm{kg})$.

$\eta_{\text {thb }}=$ Thermal efficiency of the engine, (for Diesel engine, $35 \%$,).

$427=$ Thermo-mechanical equivalent, $(\mathrm{kg} \cdot \mathrm{m} / \mathrm{k} \cdot \mathrm{cal})$.

$\eta_{\mathrm{m}}=$ Mechanical efficiency of the engine, (for Diesel engine, $85 \%$ ).

The energy can be calculated as following:

- Specific energy: Specific energy for the milling operation can be calculated as follows:

$$
\mathrm{SE}=\frac{\mathrm{Po}}{\mathrm{Mp}}, \quad \mathrm{kW} \cdot \mathrm{h} / \mathrm{kg}
$$


- Operational cost: The operational cost required for chopping and milling operation was estimated using the following equation:

$$
\mathrm{C}_{\text {op. }}=\frac{\mathrm{C}}{\mathrm{Mp}}, \quad \text { L.E. } / \mathrm{kg}
$$

Where:

$\mathrm{C}=$ Hourly cost, L.E/h.

The hourly cost of milling operation was determined using the following equation: (Awady, 1978).

$$
\mathrm{C}=\frac{\mathrm{P}}{\mathrm{h}}\left(\frac{1}{\mathrm{a}}+\frac{\mathrm{i}}{2}+\mathrm{t}+\mathrm{r}\right)+(1.2 \mathrm{~W} . \mathrm{S} . \mathrm{F})+\frac{\mathrm{m}}{144}
$$

Where:

$\mathrm{p}=$ price of machine, L.E.

$\mathrm{h}=$ yearly working hours, $\mathrm{h} /$ year

$\mathrm{a}=$ life expectancy, $\mathrm{h}$.

$\mathrm{i}=$ interest rate/year

$\mathrm{t}=$ taxes, over heads ratio.

$\mathrm{r}=$ repairs and maintenance ratio

$\mathrm{W}=$ power of motor in $\mathrm{kW}$.

$\mathrm{m}=$ monthly average wage, $\mathrm{L} . \mathrm{E}$.

$\mathrm{e}=$ hourly cost $/ \mathrm{kW} \cdot \mathrm{h}$

$144=$ monthly working hours.

\section{RESULTS AND DISCUSSION}

The obtained results will be discussed under the following items:

\subsection{Influence of chopping drum speed and stalks moisture content on cut length distribution:}

The effect of drum speed on cut length percentage is shown in Table 1. Results show that increasing drum speed from 1000 to $1400 \mathrm{rpm}$, increased cut length percentage from 39.23 to 48.21 , from 26.34 to 31.93 , from 8.00 to $10.89 \%$ at first, second and third groups respectively.

Table (1): Effect of chopping drum speed and stalks moisture content on cut length percentage.

\begin{tabular}{lcccccccc}
\hline & \multicolumn{8}{c}{ Cut length percentage, \% } \\
\cline { 2 - 9 } Cut length groups & \multicolumn{6}{c}{ Drum speed, rpm } \\
\cline { 2 - 9 } & $\mathbf{1 0 0 0}$ & $\mathbf{1 2 0 0}$ & $\mathbf{1 3 0 0}$ & $\mathbf{1 4 0 0}$ & $\mathbf{1 2}$ & $\mathbf{1 4}$ & $\mathbf{1 6}$ & $\mathbf{1 8}$ \\
\hline$<\mathbf{2}$ cm (first) & 39.23 & 41.62 & 47.37 & 48.21 & 45.12 & 47.37 & 43.76 & 40.35 \\
$\mathbf{( 2 - 4 )}$ cm (second) & 26.34 & 28.54 & 31.58 & 31.93 & 30.23 & 31.58 & 29.69 & 27.57 \\
$\mathbf{( 4 - 6 )} \mathbf{~ c m}$ (third) & 8.00 & 9.10 & 10.53 & 10.89 & 9.36 & 10.53 & 9.46 & 9.21 \\
$(\mathbf{6 - 8}) \mathbf{~ c m}$ (fourth) & 11.57 & 8.54 & 5.32 & 5.00 & 7.59 & 5.32 & 8.86 & 10.48 \\
$>\mathbf{8 ~ c m}$ (fifth) & 14.86 & 12.20 & 5.20 & 3.97 & 7.70 & 5.20 & 8.23 & 12.39 \\
\hline
\end{tabular}


While decreased cut length distribution from 11.57 to 5.00 and from 14.86 to $3.97 \%$ at fourth and fifth groups respectively, at constant feed rates of 700 $\mathrm{kg} / \mathrm{h}$. The cut length percentage increased by increasing drum speed due to the increase in chopping force and friction of the Arundo donax stalks on the cutter-head. The effect of stalks moisture content on cut length percentage is shown in table 2. Results show that increasing moisture content from 12 to $14 \%$, increased cut length percentage from 45.12 to 47.37 , from 30.23 to 31.58, from 9.36 to $10.53 \%$ at first, second and third groups respectively. While decreased cut length percentage from 7.59 to 5.32 and from 7.70 to $5.20 \%$ at fourth and fifth groups respectively. Any further increase in moisture content from 14 to $18 \%$, decreased cut length percentage from 47.37 to 40.35 , from 31.58 to 27.57 , from 10.53 to $9.21 \%$ at first, second and third groups respectively. While increased cut length percentage from 5.32 to 10.48 and from 5.20 to $12.39 \%$ at fourth and fifth groups, respectively at constant feed rate of $700 \mathrm{~kg} / \mathrm{h}$.

Higher values of stalks moisture content more than the optimum value tend to decrease the cut length percentage because of the increase in both weight and size of stalks, which forced then to move without complete chopping. On the other side, the lower values of moisture content less than the optimum value tend to decrease the cut length percentage due to the decrease in both weight and size of stalks, which cause difficulty in chopping operation.

\subsection{Influence of chopping drum speed and stalks moisture content on machine productivity at different Arundo donax feed rates:}

The effect of drum speed on machine productivity is given in Fig.2. Results show that increasing drum speed from 1000 to $1300 \mathrm{rpm}$ measured at different Arundo donax feed rates of about 500, 600, 700 and $800 \mathrm{~kg} / \mathrm{h}$, increased machine productivity from 350 to 400 , from 405 to 480 , from 528 to 600 and from 470 to $550 \mathrm{~kg} / \mathrm{h}$, respectively. Any further increase in drum speed more than 1300 up to $1400 \mathrm{rpm}$ measured at the same feed rates decreased machine productivity from 400 to 380, from 480 to 446, from 600 to 572 and from 550 to $526 \mathrm{~kg} / \mathrm{h}$, respectively at constant stalks moisture content of $14 \%$.

Concerning the effect of stalks moisture content on machine productivity, Fig.2 indicated that the increase in moisture content from 12 to $14 \%$ measured at different Arundo donax feed rates of about 500, 600, 700 and 
$800 \mathrm{~kg} / \mathrm{h}$, increased machine productivity from 370 to 400 , from 450 to 480 , from 560 to 600 and from 510 to $550 \mathrm{~kg} / \mathrm{h}$. Any Further increase in moisture content more than 14 up to $18 \%$ measured at the same feed rates decreased machine productivity from 400 to 350 from 480 to 430 , from 600 to 522 and from 550 to $492 \mathrm{~kg} / \mathrm{h}$, respectively at constant drum speed of $1300 \mathrm{rpm}$.
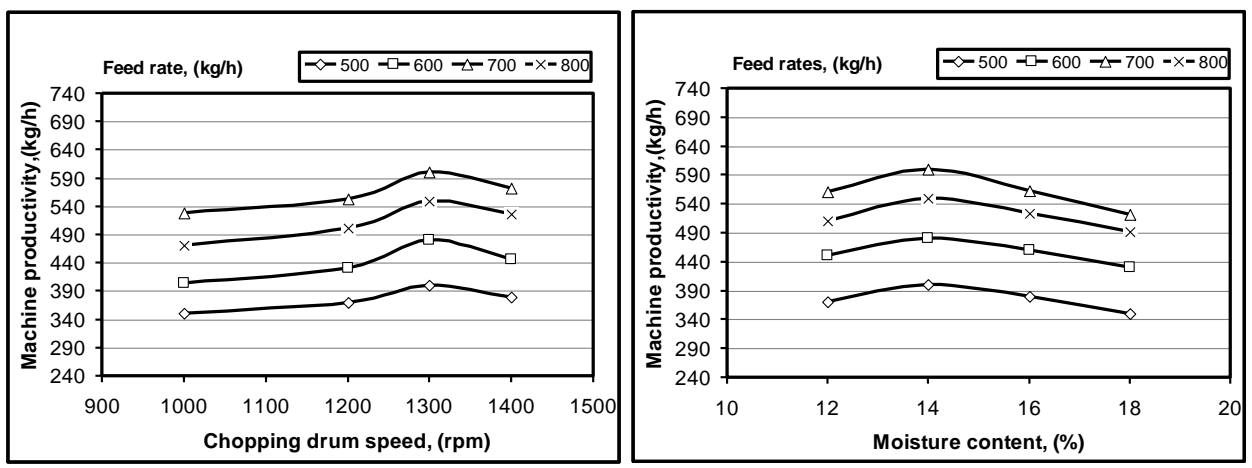

Fig.2. Effect of chopping drum speed and stalks moisture content on machine productivity at different feed rates.

The machine productivity increased by increasing chopping drum speed on account of the increase of milled Arundo donax flow through the screen openings at the same time unit. With respect to the machine productivity increased by increasing stalks moisture content due to the increase in weight of milled stalks.

\subsection{Influence of chopping drum speed and stalks moisture content on fineness degree at different Arundo donax feed rates:}

With regard to the effect of drum speed on fineness degree percentage, Fig.3 show that increasing drum speed from 1000 to $1400 \mathrm{rpm}$ measured at different feed rates of about 500,600, 700 and $800 \mathrm{~kg} / \mathrm{h}$, increased fine milled percentage from 62.24 to 74.35 , from 66.25 to 77.13 , from 73.54 to 84.44 and from 68.60 to $79.36 \%$ respectively, also increased medium milled percentage from 8.63 to 19.20 , from 6.30 to 17.00 , from 4.16 to 14.13 and from 7.10 to $18.20 \%$ respectively, while decreased coarse milled percentage from 29.13 to 6.45 , from 27.45 to 5.87 , from 22.30 to 1.43 and from 24.30 to $2.44 \%$ respectively, at constant stalks moisture content of $14 \%$. The fineness degree increased by increasing drum speed due to the increase in chopping and milling forces and friction of the Arundo donax stalks on the cutter-head and hammer mill. 

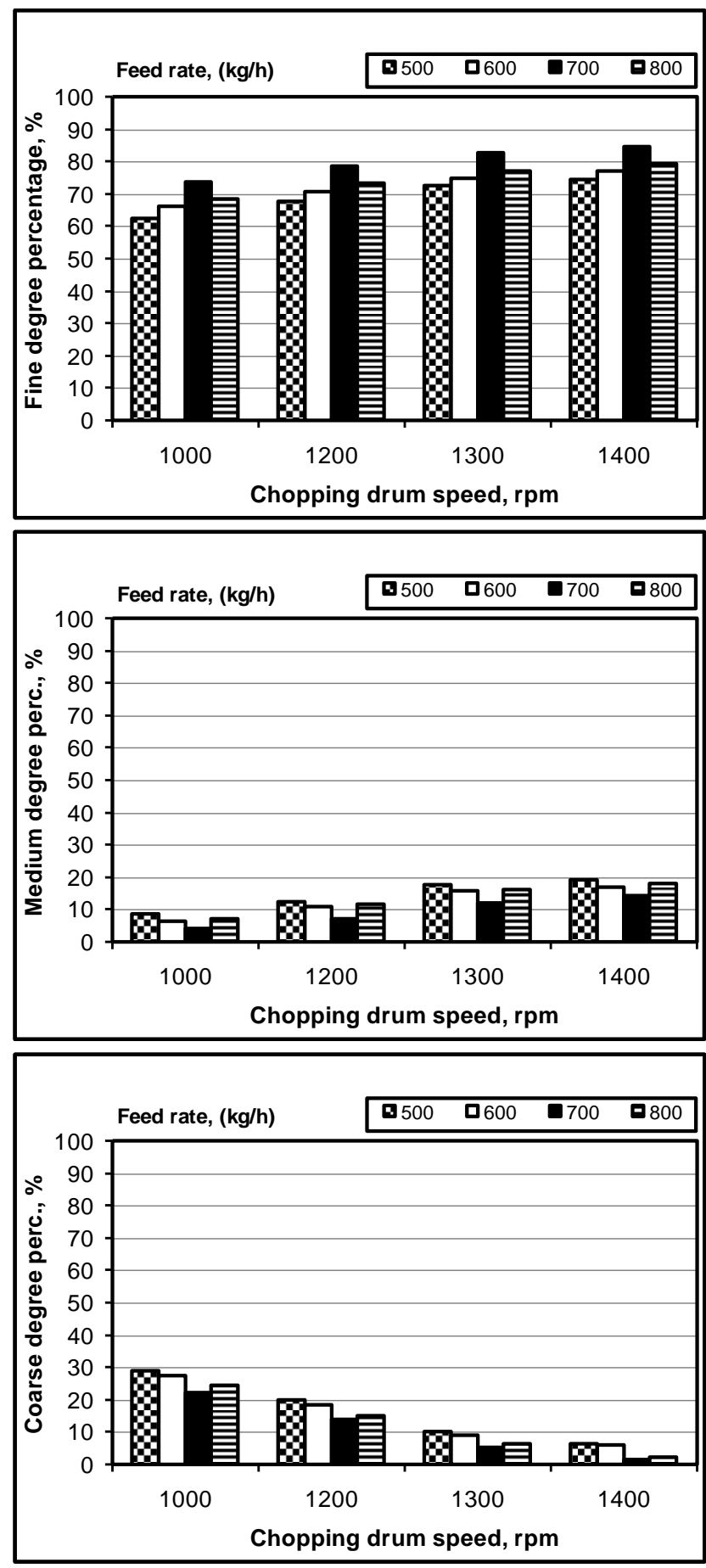

\section{Fig.3. Effect of chopping drum speed on fineness degree at different Arundo donax feed rates.}


In respect the effect of moisture content on fineness degree, results in Fig.4 show that increasing stalks moisture content from 12 to $14 \%$ measured at different feed rates of about 500,600, 700 and $800 \mathrm{~kg} / \mathrm{h}$, increased fine milled percentage from 65.55 to 72.40 , from 68.30 to 75.00 , from 76.83 to 82.87 and from 71.45 to $77.20 \%$, respectively.

Also increased medium milled percentage from 11.24 to 17.56 , from 9.60 to 15.80, from 6.65 to 12.05 and from 10.43 to $16.26 \%$, respectively, while decreased coarse milled percentage from 23.21 to 10.04 , from 22.10 to 9.20 , from 16.52 to 5.08 and from 18.12 to $6.54 \%$, respectively.

While any further increase in moisture content more than 14 up to $18 \%$ measured at the same feed rates decreased fine milled percentage from 72.40 to 64.30 , from 75.00 to 68.42 , from 82.87 to 75.62 and from 77.20 to 70.55 $\%$, respectively, also decreased medium milled percentage from 17.56 to 7.35, from 15.80 to 5.22 , from 12.05 to 3.11 and from 16.26 to $6.23 \%$, respectively, while increased coarse milled percentage from 10.04 to 28.35 , from 9.20 to 26.36 , from 5.08 to 21.27 and from 6.54 to $23.22 \%$, respectively at constant chopping drum speed of $1300 \mathrm{rpm}$.

Higher values of stalks moisture content more than the optimum value tend to decrease fineness degree because of the increase in both weight and size of stalks, which forced then to move through the screen openings without complete milling. On the other side, the lower values of moisture content less than the optimum value tend to decrease fineness degree due to the decrease in both weight and size of stalks, which cause difficulty in milling operation.

\subsection{Influence of chopping drum speed and stalks moisture content on specific energy at different feed rates:}

As regard the effect of drum speed, Fig.5 show that increasing drum speed from 1000 to $1300 \mathrm{rpm}$ measured at different feed rates of about 500, 600, 700 and $800 \mathrm{~kg} / \mathrm{h}$, decreased specific energy from 121.86 to 106.63 , from 105.31 to 88.85 , from 80.78 to 71.08 and from 90.74 to $77.55 \mathrm{~kW} . \mathrm{h} / \mathrm{Mg}$, respectively. Any further increase in drum speed from 1300 to $1400 \mathrm{rpm}$, specific energy will increase from 106.63 to 112.24 , from 88.85 to 95.63 , from 71.08 to 74.56 and from 77.55 to $81.08 \mathrm{~kW} . \mathrm{h} / \mathrm{Mg}$, respectively at constant stalks moisture content of $14 \%$.

With respect to the effect of moisture content on specific energy, results in Fig. 6 show that increasing moisture content from 12 to $14 \%$ measured at 

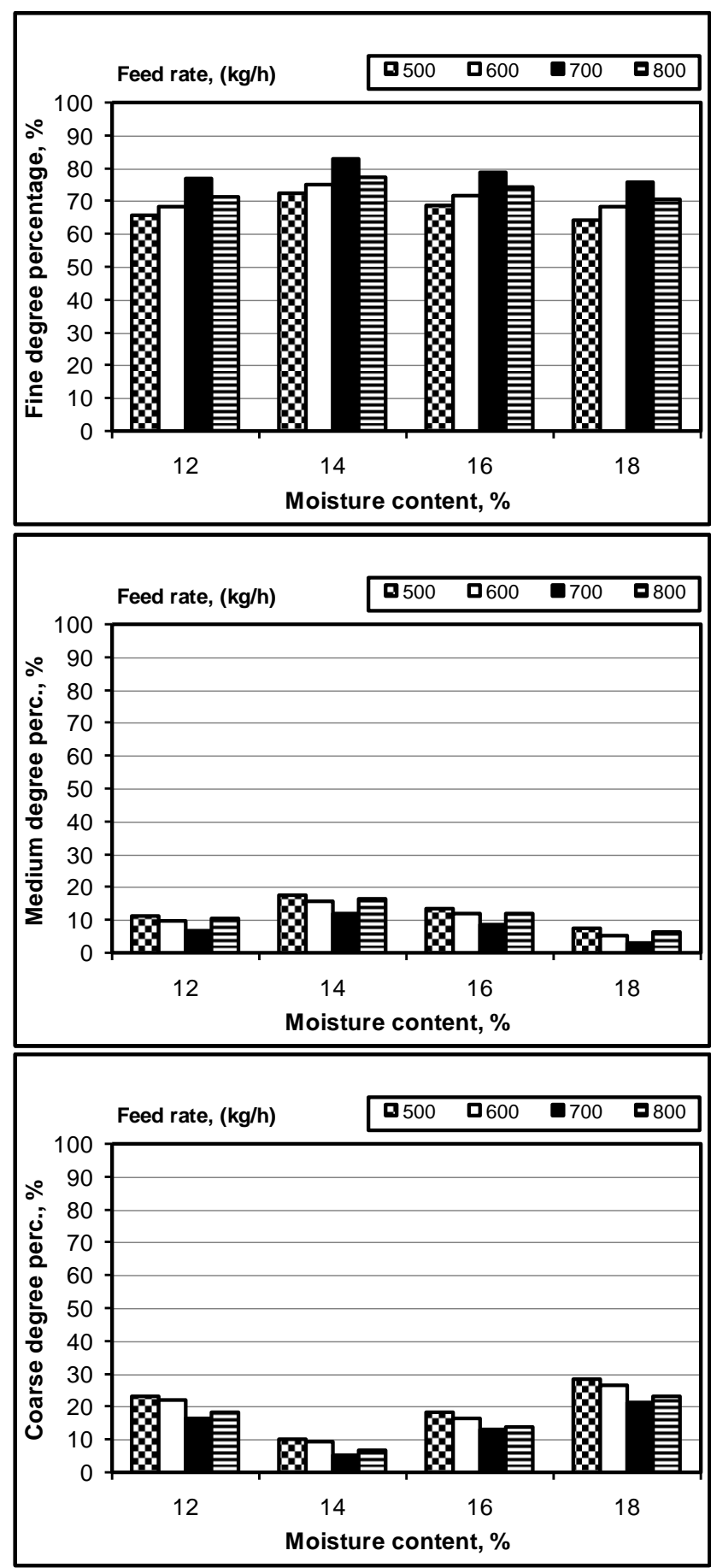

Fig.4. Effect of moisture content on fineness degree at different Arundo donax feed rates. 

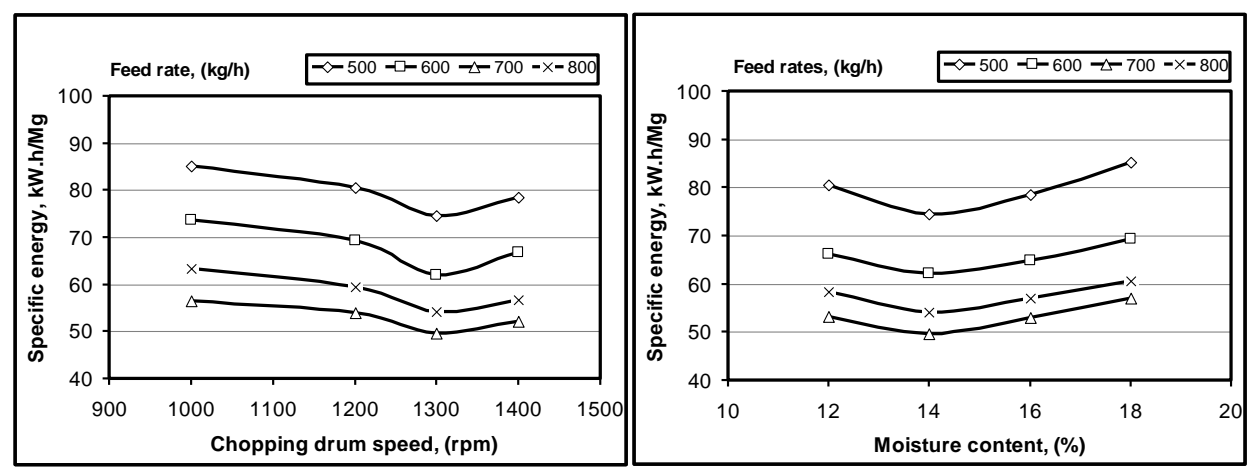

Fig.5. Effect of drum speed and moisture content on specific energy at different Arundo donax feed rates.

different feed rates of about 500,600, 700 and $800 \mathrm{~kg} / \mathrm{h}$, decreased specific energy from 115.27 to 106.63 , from 94.78 to 88.85 , from 76.16 to 71.08 and from 83.63 to $77.55 \mathrm{~kW} . \mathrm{h} / \mathrm{Mg}$, respectively. Any further increase in moisture content from 14 to $18 \%$, specific energy will increase from 106.63 to 121.86 , from 88.85 to 99.19 , from 71.08 to 81.70 and from 77.55 to $86.69 \mathrm{~kW} . \mathrm{h} / \mathrm{Mg}$, respectively at constant drum speed of $1300 \mathrm{rpm}$. The higher values of chopping drum speed and stalk moisture content more than the optimum values tend to increase the specific energy due to the decrease in machine productivity.

\subsection{Influence of chopping drum speed and stalks moisture content on operational cost at different feed rates:}

As to the effect of drum speed, Fig. 6 show that increasing drum speed from 1000 to $1300 \mathrm{rpm}$ measured at different feed rates of about 500, 600, 700 and $800 \mathrm{~kg} / \mathrm{h}$, decreased operational cost from 57.14 to 50.00 , from 49.38 to 41.67, from 37.88 to 33.33 and from 42.55 to $36.36 \mathrm{~L} . \mathrm{E} / \mathrm{Mg}$, respectively. Any further increase in drum speed from 1300 to $1400 \mathrm{rpm}$, operational cost will increase from 50.00 to 52.63 , from 41.67 to 44.84 , from 33.33 to 34.97 and from 36.36 to 38.02 L.E./Mg at constant stalks moisture content of $14 \%$. In respect to the effect of moisture content on operational cost, results in Fig.7 show that increasing moisture content from 12 to $14 \%$ measured at different feed rates of about 500,600, 700 and $800 \mathrm{~kg} / \mathrm{h}$, decreased operational cost from 54.05 to 50.00 , from 44.44 to 41.67 , from 35.71 to 33.33 and from 39.22 to $36.36 \mathrm{~L} . \mathrm{E} / \mathrm{Mg}$, respectively. Any further increase in moisture content from 14 to $18 \%$, operational cost will increase from 50.00 
to 57.14 , from 41.67 to 46.51 , from 33.33 to 38.31 and from 36.36 to 40.65 L.E./Mg at constant drum speed of $1300 \mathrm{rpm}$. Both higher and lower values of chopping drum speed and stalk moisture content more or less than the optimum value tend to increase operational cost due to the decrease in machine productivity.
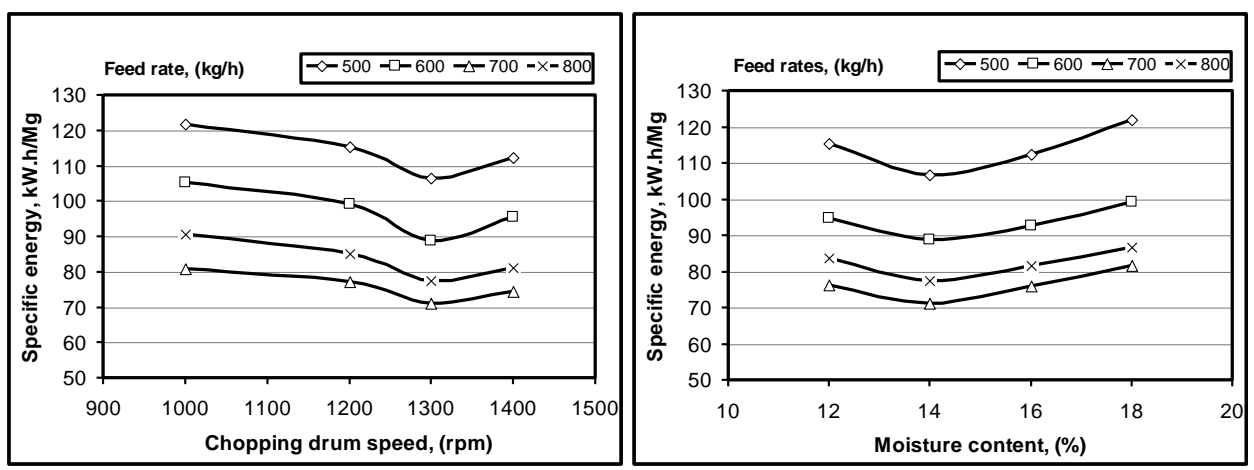

Fig.6. Effect of drum speed and moisture content on operational cost at different Arundo donax feed rates.

\section{CONCLUSION}

The combination machine for chopping and milling the Arundo donax stalks was manufactured from locally available materials in a private workshop in Zagazig city and evaluated at Agricultural Engineering Department for producing milled Arundo donax so as to use the final product in many industrial applications. The obtained results reveal that the maximum values of machine productivity and fines degree were $(600 \mathrm{~kg} / \mathrm{h}$ and $82.87 \%)$, while the minimum values of the specific energy and operational cost were (71.08 $\mathrm{kW} . \mathrm{h} / \mathrm{Mg}$ and $33.33 \mathrm{L.E} / \mathrm{Mg}$ ), respectively under the following conditions: drum speed of about $1300 \mathrm{rpm}$, stalks moisture content of $14 \%$ with adjusting feed rate at $700 \mathrm{~kg} / \mathrm{h}$.

\section{REFERRENCES}

Awady, M. N. (1978): Tractor and farm machinery. Text book, Faculty of Agriculture, Ain-Shams University. Pp: 164-167.

Elfatih, A; E. M. Arif and, A. E. Atef (2010): Evaluate the Modified Chopper for Rice Straw Composting. Journal of Applied Sciences Research, 6(8): 1125-1131.

Guthrie, G. (2007): Impacts of the invasive reed Arundo donax on biodiversity at the community-ecosystem level. M. Sc. Thesis. 
Biodiversity and Conservation Biology Department, Faculty of Natural Sciences, University of the Western Cape, South Africa.

Heaton, E; T. Voigt and S. P. Long (2004): A quantitative review comparing the yields of two candidate $\mathrm{C}_{4}$ perennial biomass crops in relation to nitrogen, temperature and water. Biomass and Bioenergy. 27: 21-30.

Henderson, S. M. and P. L. Hansen (1968): Hammer mill and Burr mill performance analyzed. Trans. of the ASAE., 11(3): 399-402.

Hunt, D. (1983): Farm power and machinery management. $8^{\text {th }}$ Ed. Iowa state Univ., Press Ames, USA. Ames, Iowa, USA: 364-368.

Pilu, R; A. Bucci, F. Cerino Badone and M. Landoni (2012): Giant Reed (Arundo donax L): a weed plant or a promising energy crop? Afr $\mathbf{J}$ Biotechnol 11: 9163-9174.

Solomon Tekeste (2012): A design study of a motor-driven chopper for chopping crop residue and hay. The IUP Journal of Mechanical Engineering, Vol. V, No. 3, pp. 68-75.

Spencer, D. F; P. Liow, W. K. Chan, G. G. Ksander and K. D. Getsinger (2006): Estimating Arundo donax shoot biomass. Aquatic Botany, 84: 272-276.

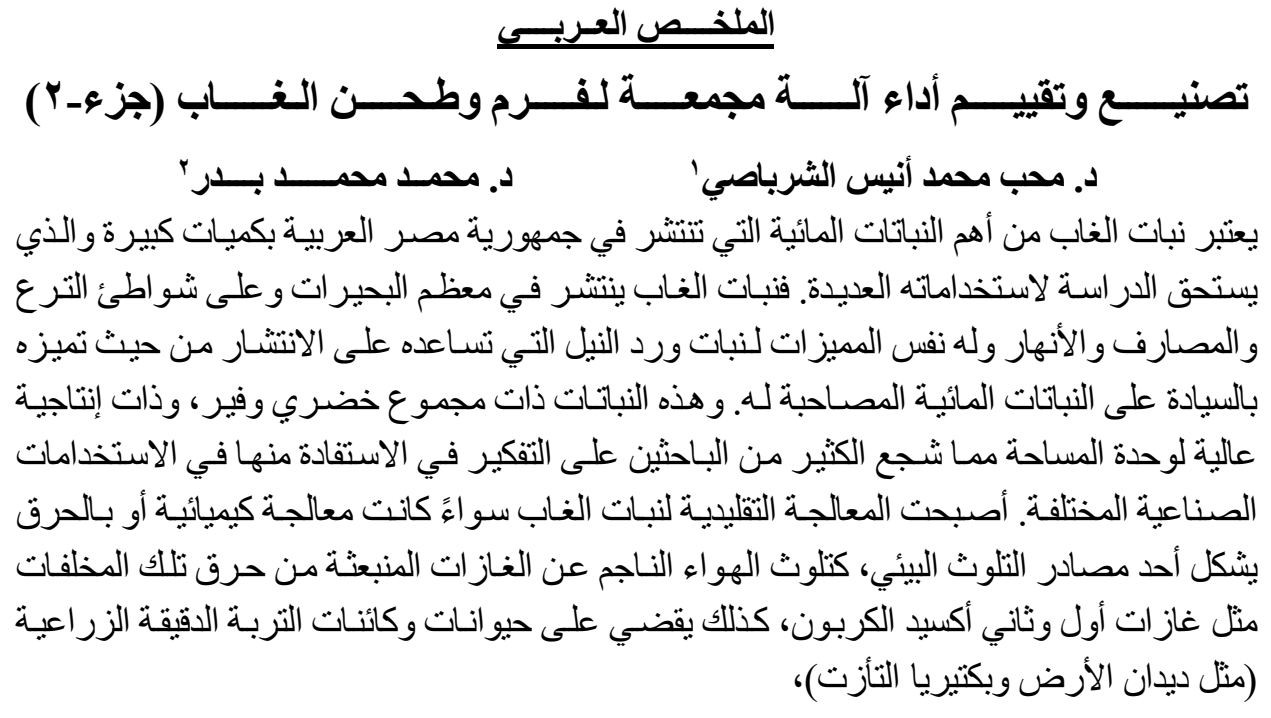

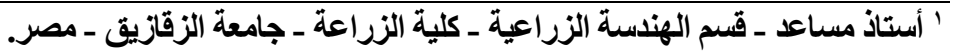

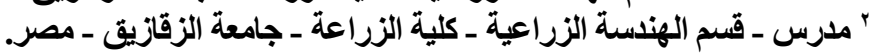


فضلاً عن عدم الاستفــادة من هذا المخلـف في عـــدة مجـالات وذللك بتحويلها إلى أسمدة عضوية

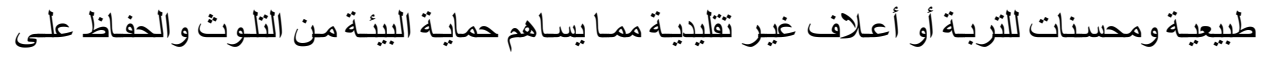

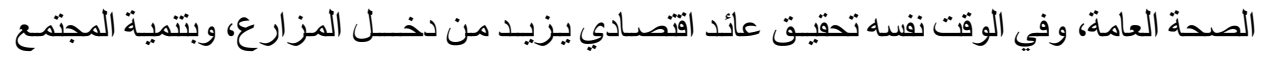

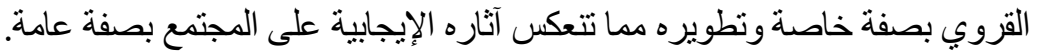

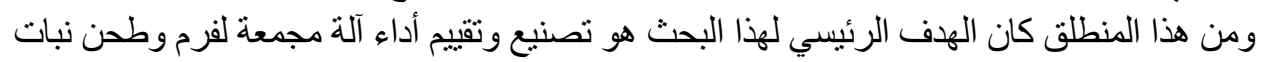
الغاب ومن ثم يمكن استخدام نواتج الفرم بعد المعالجة في تغذية الحيو انات كعلف غير تقليدي كما يمكن أيضاً استخدام نواتج الطحن في العديد من الصناعات المختلفة كإنتاج الكمبوست العضوي ومحسنات التربة وإنتاج بيئات زراعية وإنتاج الأخشاب المضغوطة. تمت عملية التصنيع بإحدى الته الورش الخاصة بقرية الطاهرة ـ مركز الزقازيق ـ محافظة الثرقية من خامات محلية الصنع بغية تحقيق التتمية الاقتصادية بأقل تكلفة ممكنة. تم تتفيذ التجارب بقسم الهندة الزراعية ـ كلية الزراعة ـ جامعة الزقازيق لتقييم أداء هذه الآلة للوصول إلى أفضل القيم التشغيلية لتحقيق أعلى إنتاجية بأقل تكلفة ممكنة.

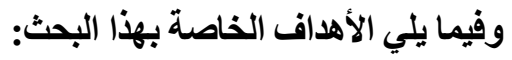

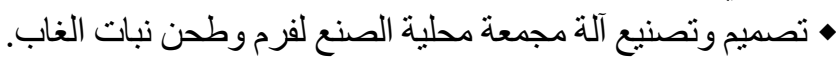

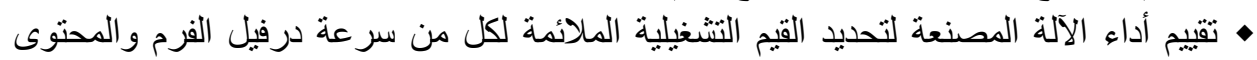
الرطوبي للسيقان ومعدلات التلقيم و التي تحقق أعلى إنتاجية بأقل تكلفة لتشغيل التحنية الآلة.

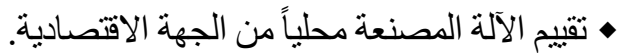
ولدر اسة أداء الآلة تم أخذ بعض المعاملات التالية في الاعتبار: أربع سرعات مختلفة لدرفيل الفرم

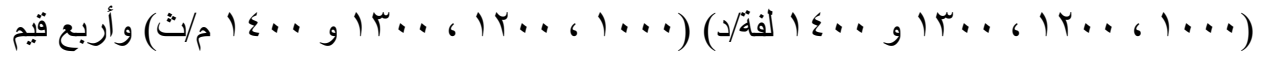

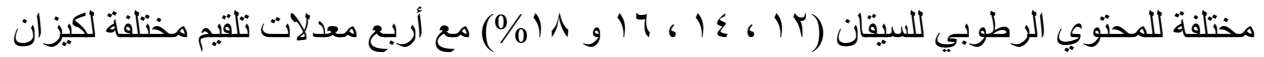

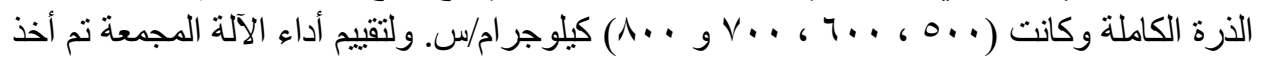

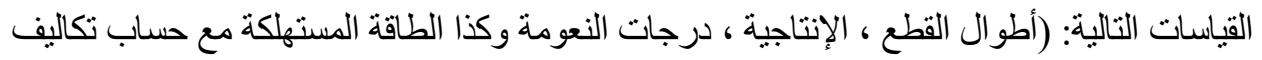

(التشغيل).

وق أظهرت النتائج المتحصل عليها ما يلي:

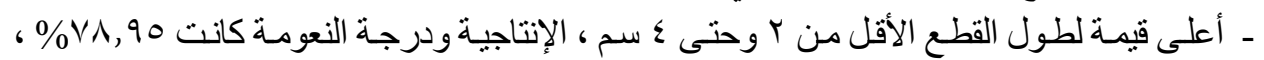

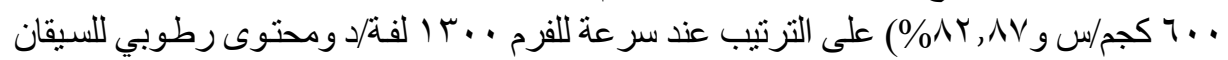

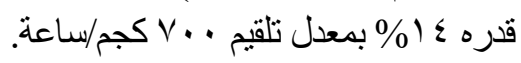

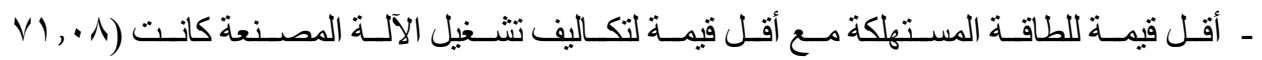
كيلوات.س/ميجاجر ام و سب, سم جنيه/ميجاجر ام)، على الترتيب عند نفس ظروف النشغيل السابقة.

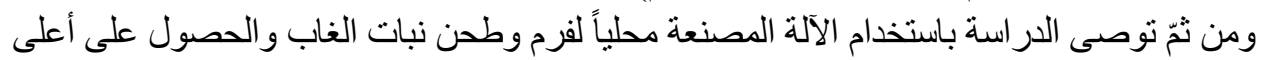

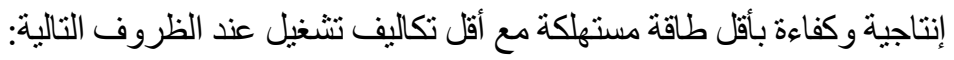
• • معدل تلقيم قدره ( • V كجم/ساعة).

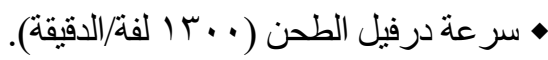

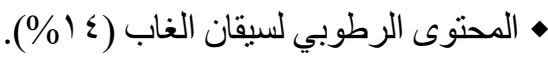

